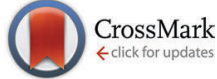

Cite this: Phys. Chem. Chem. Phys., 2014, 16, 21804

Received 1st August 2014,

Accepted 18th August 2014

DOI: $10.1039 / \mathrm{c} 4 \mathrm{cp} 03430 \mathrm{a}$

www.rsc.org/pccp

\section{Effect of low thermal budget annealing on surface passivation of silicon by ALD based aluminum oxide films}

\author{
Vandana,* Neha Batra, Jhuma Gope, Rajbir Singh, Jagannath Panigrahi, \\ Sanjay Tyagi, $\dagger$ P. Pathi, S. K. Srivastava, C. M. S. Rauthan and P. K. Singh*
}

\begin{abstract}
Thermal ALD deposited $\mathrm{Al}_{2} \mathrm{O}_{3}$ films on silicon show a marked difference in surface passivation quality as a function of annealing time (using a rapid thermal process). An effective and quality passivation is realized in short anneal duration ( 100 s) in nitrogen ambient which is reflected in the low surface recombination velocity (SRV $<10 \mathrm{~cm} \mathrm{~s}^{-1}$ ). The deduced values are close to the best reported SRV obtained by the high thermal budget process (with annealing time between 10-30 min), conventionally used for improved surface passivation. Both as-deposited and low thermal budget annealed films show the presence of positive fixed charges and this is never been reported in the literature before. The role of field and chemical passivation is investigated in terms of fixed charge and interface defect densities. Further, the importance of the annealing step sequence in the MIS structure fabrication protocol is also investigated from the view point of its effect on the nature of fixed charges.
\end{abstract}

\section{Introduction}

In a semiconductor, recombination losses occur largely via defect levels within the band gap. These defects are located in the bulk material and at the surfaces (largely due to the presence of dangling bonds). The reduction of such losses is of prime importance for numerous photonic devices such as light emitting diodes, photo-detectors and photovoltaic cells. ${ }^{1}$ The losses emanating from the two surfaces can be reduced by surface passivation and is an area to be addressed for making efficient next generation devices. In order to reduce the cost of silicon solar cells made on expensive wafers (high quality silicon), thinner substrates (to reduce the usage in terms of watt $\mathrm{g}^{-1}$ ) are required. ${ }^{2,3}$ A reduction in thickness and surface modification (either by anisotropic ${ }^{4}$ or nano-texturisation ${ }^{5}$ ) to reduce reflection losses leads to the increase of the surface to volume ratio and, consequently, the surface recombination becomes a dominant loss factor. ${ }^{6}$ This affects the solar cell performance parameters adversely. Recently, surface passivation is becoming increasingly important to enhance the performance of both single crystal (c-Si) and multi-crystalline silicon (mc-Si) solar cells. ${ }^{2}$ Passivation reduces surface recombination losses by two ways, i.e., chemical passivation (reduction of the density of

Silicon Solar Cell Group, (Network of Institutes for Solar Energy), CSIR - National Physical Laboratory, New Delhi-110012, India. E-mail: vandana1@nplindia.org, pksingh@nplindia.org

$\dagger$ The author is working at Central Electronics Limited, Sahibabad, India. electronic surface states) and field effect passivation (the presence of fixed charges in the dielectric layer over the silicon surface that reduces the carrier density underneath the interface of the two). ${ }^{1,7-10}$ A well passivated surface reduces the recombination of photo-generated carriers in the vicinity of the two surfaces and improves the cell performance parameters. ${ }^{11-14}$ Thermally grown silicon oxide $\left(\mathrm{SiO}_{2}\right)$, silicon nitride $\left(\mathrm{a}-\mathrm{SiN}_{x}: \mathrm{H}\right)$ and amorphous silicon (a-Si:H) are commonly used for surface passivation of c-Si solar cells. ${ }^{15-21}$ Aluminum oxide $\left(\mathrm{Al}_{2} \mathrm{O}_{3}\right)$, a dielectric, has excellent surface passivation properties on c-Si of both conductivity type materials. ${ }^{7-9}$ Recently $\mathrm{Al}_{2} \mathrm{O}_{3}$ films have been used to passivate the silicon surface to achieve high efficiency solar cells. ${ }^{11-14}$ There are several methods for $\mathrm{Al}_{2} \mathrm{O}_{3}$ film deposition, e.g., sputtering, ${ }^{22}$ atmospheric pressure chemical vapor deposition, ${ }^{23}$ RF magnetron sputtering ${ }^{24}$ and plasma enhanced chemical vapour deposition, ${ }^{25,26}$ etc. Atomic layer deposition (ALD) has been proven to be a valuable technique for the growth of $\mathrm{Al}_{2} \mathrm{O}_{3}$ thin films. ${ }^{27}$ ALD is a conformal coating technique, by which a high level of control over film thickness and uniformity can be achieved besides being a low temperature process. There are several reports related to the surface passivation property of $\mathrm{Al}_{2} \mathrm{O}_{3}$ films deposited using thermal ALD process. ${ }^{1,7-9}$ The measure of surface passivation is surface recombination velocity (SRV) which can be deduced from the measured minority carrier lifetime values. Although in some papers, low $\mathrm{SRV}$ is obtained in as-deposited $\mathrm{Al}_{2} \mathrm{O}_{3}$ films, ${ }^{28}$ however, high quality surface passivation is realized after post deposition annealing. ${ }^{1,7-9}$ Normally 30 min post-deposition 
annealing at $400{ }^{\circ} \mathrm{C}$ is required to get good surface passivation. To the best of our knowledge, low thermal budget annealing is very scantly reported in the literature. Further, the reported studies in the past are different in terms of deposition parameters and conditions, therefore, show different performances in as-deposited and annealed states. All this indicates that the passivation mechanism is not yet fully understood and is not straightforward for as-deposited and annealed films. The overall performance is explained either individually or as a combined effect of chemical and field effect passivation which are described in terms of interface defect and fixed charge densities respectively. ${ }^{1,7-9}$

In this paper, the study of c-Si surface passivation by $\mathrm{Al}_{2} \mathrm{O}_{3}$ film is reported. The $\mathrm{Al}_{2} \mathrm{O}_{3}$ films of different thickness are deposited to optimize post-annealing time $\left(t_{\mathrm{anl}}\right)$ at a fixed annealing temperature $\left(T_{\mathrm{anl}}=400{ }^{\circ} \mathrm{C}\right)$. The effect of the film thickness on effective minority carrier lifetime and refractive index is investigated. The minority carrier lifetime is measured from which $\mathrm{SRV}$ values (at $\mathrm{Al}_{2} \mathrm{O}_{3} / \mathrm{Si}$ interface) are deduced which defines effectiveness of surface passivation. $C-V$ measurements are used to find the flat band voltage $\left(V_{\mathrm{FB}}\right)$, density of fixed charges $\left(Q_{\mathrm{F}}\right)$ and interface defects $\left(D_{\mathrm{it}}\right)$.

\section{Experimental}

To grow $\mathrm{Al}_{2} \mathrm{O}_{3}$ thin films, trimethylaluminum [TMA, $\left(\mathrm{Al}\left(\mathrm{CH}_{3}\right)_{3}\right)$ ] (procured from $\mathrm{M} / \mathrm{s}$ SAFC, Hitech, UK) and $\mathrm{H}_{2} \mathrm{O}$ (deionised water of $18.3 \mathrm{M} \Omega \mathrm{cm}$ ) are the precursors used for aluminum and oxygen sources respectively. The films are deposited in a thermal ALD reactor (Model: R200, M/s Picosun, Finland). The films are grown on float zone (FZ) n- and p-Si (325 $\pm 10 \mu \mathrm{m}$ thick) substrates of (100) orientation and resistivity $(5 \pm 0.5 \Omega \mathrm{cm})$. In order to ensure exactly the same optical and electronic properties, each sample is a quarter diced from chemically mechanically polished (CMP) $100 \mathrm{~mm}$ diameter wafer. The samples are cleaned with piranha solution ( $\mathrm{PC}, \mathrm{H}_{2} \mathrm{SO}_{4}: \mathrm{H}_{2} \mathrm{O}_{2}:: 4: 1$ solution for $15 \mathrm{~min}$ ) followed by $2 \mathrm{~min}$ dip in diluted $\mathrm{HF}$ ( $5 \%$ solution). A single deposition cycle in the ALD system consists of two half cycles; one TMA pulse and the other $\mathrm{H}_{2} \mathrm{O}$ pulse and each half cycle is separated by a nitrogen purge step. During each cycle, one monolayer of the material is formed and as the number of cycle progresses, the number of mono-layers grows one over another. After deposition of the desired thickness of the layer on one side, the sample is flipped after taking it out from the deposition chamber to load lock, in order to get the film deposited on the rear side also. The film of the same thickness is grown on the rear side. Samples $\left(S_{1}-S_{5}\right)$ of various thicknesses are prepared by varying the number of deposition cycles (details are given in Table 1). The substrate temperature $\left(T_{\text {sub }}\right)$ is fixed at $300{ }^{\circ} \mathrm{C}$ during the deposition. Post-deposition annealing $\left(T_{\text {anl }}\right)$ is carried out at $400{ }^{\circ} \mathrm{C}$ (commonly used and optimized during the course of study) in nitrogen ambient by rapid thermal processing (RTP Model: AS-one 150, M/s Annealsys, France).

The film thickness $\left(d_{\mathrm{Al}_{2} \mathrm{O}_{3}}\right)$ and refractive index $\left(n_{\mathrm{Al}_{2} \mathrm{O}_{3}}\right)$ are measured by a spectroscopic ellipsometer (Model: M2000, M/s
Table 1 The number of precursor cycles and corresponding film thickness $\left(d_{\mathrm{Al}_{2} \mathrm{O}_{3}}\right)$ and refractive index $\left(n_{\mathrm{Al}_{2} \mathrm{O}_{3}}\right)$ of films made on $\mathrm{n}-\mathrm{Si}$

\begin{tabular}{lcll}
\hline Sample & No. of cycles & Thickness $(\mathrm{nm})$ & Refractive index \\
\hline $\mathrm{S}_{1}$ & 1000 & 93.1 & 1.65 \\
$\mathrm{~S}_{2}$ & 500 & 48.0 & 1.64 \\
$\mathrm{~S}_{3}$ & 300 & 30.1 & 1.62 \\
$\mathrm{~S}_{4}$ & 100 & 11.2 & 1.53 \\
$\mathrm{~S}_{5}$ & 50 & 7.2 & 1.50
\end{tabular}

J.A. Wollam Co. Inc., USA). The reflectivity of the films is measured using a spectrophotometer fixed with an integrating sphere (Model: PVE 300, M/s Benthem, UK with an integrating sphere DTR6). To ensure the correctness of the measured reflectivity values, the measurements are done after baseline (i.e., back ground) correction using standard high purity $\mathrm{BaSO}_{4}$ powder pressed in the form of a pallet. Fourier transform infrared spectroscopy (Model 2000, M/s Perkin Elmer spectrometer, USA) is used to get information about the surface bonding.

The minority carrier lifetime $\left(\tau_{\text {eff }}\right)$ is measured using the photo-conductance decay method (Model: WCT-120, Sinton lifetime tester) and the uniformity of $\tau_{\text {eff }}$ is examined by mapping the lifetime parameter using a microwave photoconductive decay system ( $\mu \mathrm{W}-\mathrm{PCD}$, Model: WT 2000, M/s Semilab Zrt, Hungary). $\tau_{\text {eff }}$ measured by Sinton's lifetime tester is an effective average value of carrier lifetime. In this tool, excess carriers are generated by a flash and the sheet conductivity is measured by RF coil inductively coupled to the sample. The flash intensity and sheet conductivity are converted into a generation rate of electron-hole $(\mathrm{e}-\mathrm{h})$ pairs and the average excess carrier density by using the mobility model. ${ }^{29}$ In the WCT-120 injection levels $(\Delta n)$ can be varied in a wide range $\left(10^{13}<\Delta n<10^{16} \mathrm{~cm}^{-3}\right)$. The system operates in (i) quasi steady state photo-conductance (QSSC) and (ii) transient photo-conductance (TPC) decay modes. In the QSSC mode, the decay constant of the flash should be at least 10 times slower than the carrier lifetime so that the population of excess carriers attains a steady state and hence, the lifetime is measured under steady state conditions. In the transient mode, the fast pulse of light which peaks and decays back in $\sim 15 \mu \mathrm{s}$ is used and the photo-conductance decay is measured to determine the effective carrier lifetime. This mode is suitable for high lifetime materials. Transient mode is used when the measured lifetime values are more than $200 \mu \mathrm{s}$ and the quasi steady state mode is used in the low lifetime values. ${ }^{30}$ To see the lifetime uniformity, measurements are also made using $\mu \mathrm{W}$-PCD which has a $904 \mathrm{~nm}$ pulsed laser (penetration depth $>30 \mu \mathrm{m}$ ) and a microwave source operating at $10 \mathrm{GHz}$ are used. The former is for optical excitation and the later for signal detection (where decay of the excess carrier concentration is monitored by the microwave reflectance). In this system the injection level is fixed $\left(\Delta n=1.2 \times 10^{13} \mathrm{~cm}^{-3}\right)$. Hence, the measured $\tau_{\text {eff }}$ by the WCT- 120 and the $\mu \mathrm{W}$-PCD could be compared at the same injection levels. ${ }^{31}$

The metal-insulator-semiconductor (MIS) structure (schematic of which is given in Fig. 1) is fabricated by depositing aluminum dots (area $\sim 0.02 \mathrm{~cm}^{2}$ ) using an e-beam evaporation system 


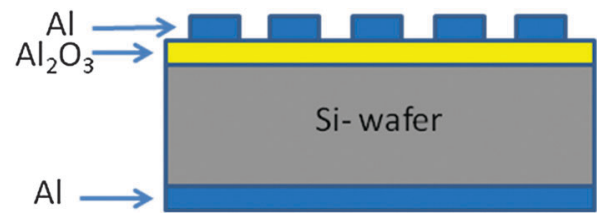

Fig. 1 Schematic of the MIS structure. Different thicknesses of $\mathrm{Al}_{2} \mathrm{O}_{3}$ layers are used.

(M/s Hind Hivac, India). The capacitance-voltage $(C-V)$ measurements are performed with an impedance/gain phase analyzer (Model: 1260, M/s Solartron, UK).

\section{Results and discussion}

\subsection{Film thickness and the refractive index}

The atomic force (AFM) and scanning electron (SEM) microscopes studies reveal that the ALD deposited films are highly conformal and uniform. A typical atomic force micrograph of $\mathrm{S}_{3}$ is given in Fig. 2. The RMS surface roughness is $\sim 5 \AA$ which is almost the same as that of the substrate (chemically mechanically polished silicon wafer) within measurement uncertainty.

The measured film thickness and refractive index as a function of number of deposition cycles are shown in Fig. 3. A linear growth (@0.09 nm per cycle) of film thickness as a function of the number of process cycles is observed which is indicative of highly controlled film growth. The refractive index

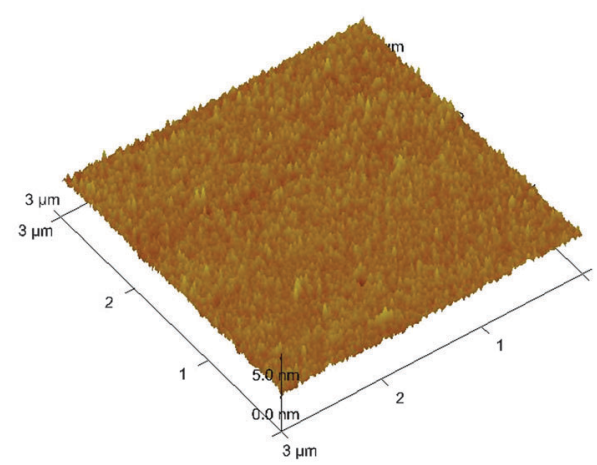

Fig. 2 AFM micrograph of $\mathrm{S}_{3}$ with $30 \mathrm{~nm}$ thick $\mathrm{Al}_{2} \mathrm{O}_{3}$ layer on CMP wafer.

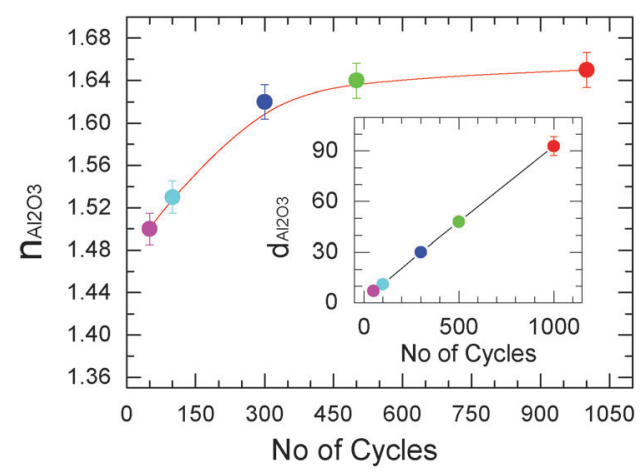

Fig. 3 Refractive index as a function of the number of ALD cycles. The inset shows film thickness (in $\mathrm{nm}$ ) with number of cycles. also changes with the number of cycles and increases with increase in the film thickness. Refractive index values are rather low at lower film thicknesses and stabilizes for $d_{\mathrm{Al}_{2} \mathrm{O}_{3}} \sim 30 \mathrm{~nm}$. The ellipsometric measurements at times are sensitive to a perturbation parameter at low thicknesses. ${ }^{32}$ In the reported values, this aspect is taken care by the error bars. The measured $d_{\mathrm{Al}_{2} \mathrm{O}_{3}}$ and $n_{\mathrm{Al}_{2} \mathrm{O}_{3}}$ values are effective values rather than the true estimation of the parameters (as described below).

Although $\mathrm{Al}_{2} \mathrm{O}_{3}$ is thermodynamically stable on silicon, however, growth of a $\mathrm{SiO}_{2}$ or an aluminum silicate layer at the $\mathrm{Al}_{2} \mathrm{O}_{3} / \mathrm{Si}$ interface is inevitable as the growth occurs under non-equilibrium conditions. $^{27}$ It is observed that initially the thickness of the interfacial layer increases and stabilizes at 1-2 $\mathrm{nm}^{7,27}$ during $\mathrm{Al}_{2} \mathrm{O}_{3}$ film growth. The interfacial layer affects the refractive index and the measured $n_{\mathrm{Al}_{2} \mathrm{O}_{3}}$ may be that of the $\mathrm{Al}_{2} \mathrm{O}_{3}-\mathrm{SiO}_{2}$ composite layer. The low refractive index for thinner $\mathrm{Al}_{2} \mathrm{O}_{3}$ ALD film thicknesses is attributed to this interfacial layer. Once the thickness of the interfacial layer stabilizes, the value of $n$ is close to the refractive index of bulk alumina $(\sim 1.77)$ within measurement error and the measured value is close to the values reported in ALD deposited $\mathrm{Al}_{2} \mathrm{O}_{3}$ films. ${ }^{27}$ The annealing of the films does not change either the thickness or the refractive index. This further reiterates the conformity and compactness of the thermally grown films. The typical monolayer thickness of $\mathrm{Al}_{2} \mathrm{O}_{3}$ is $0.3 \mathrm{~nm}$ and the growth rate $0.09 \mathrm{~nm}$ per cycle is quite low, albeit similar growth rates are given in the literature. ${ }^{27}$

\subsection{Reflectivity}

Fig. 4 shows spectral dependence of the reflectivity $\left(R_{\lambda}\right)$ of samples $\mathrm{S}_{1}-\mathrm{S}_{4}$ along with that of reference CMP silicon wafer. It is observed that surface reflectivity does not change much at a lower $\mathrm{Al}_{2} \mathrm{O}_{3}$ thickness $(<10 \mathrm{~nm})$ and is close to the value of the CMP sample, but the increase in $d_{\mathrm{Al}_{2} \mathrm{O}_{3}}$ reduces $R_{\lambda}$. An overall reduction in $R_{\lambda}$ is observed in a 400 to $1050 \mathrm{~nm}$ range. However, minima of $R_{\lambda}$ shifts from $\sim 400 \mathrm{~nm}$ to $\sim 600 \mathrm{~nm}$ with change in the film thickness from $\sim 30 \mathrm{~nm}$ to $\sim 93 \mathrm{~nm}$. The average reflectance reduces from $32.8 \%$ (CMP-Si) to $32.13 \%$, $27.98 \%, 21.4 \%$, and $16.8 \%$ respectively for samples $\mathrm{S}_{4}, \mathrm{~S}_{3}, \mathrm{~S}_{2}$ and $\mathrm{S}_{1}$. The minimum $R_{\lambda}$ is $\sim 4 \%$ for sample $\mathrm{S}_{1}$. This trend is expected in single layer coating.

The position (wavelength, $\lambda_{\text {min }}$ ) of the minimum in $R_{\lambda}$ is related to the thickness and the refractive index by the

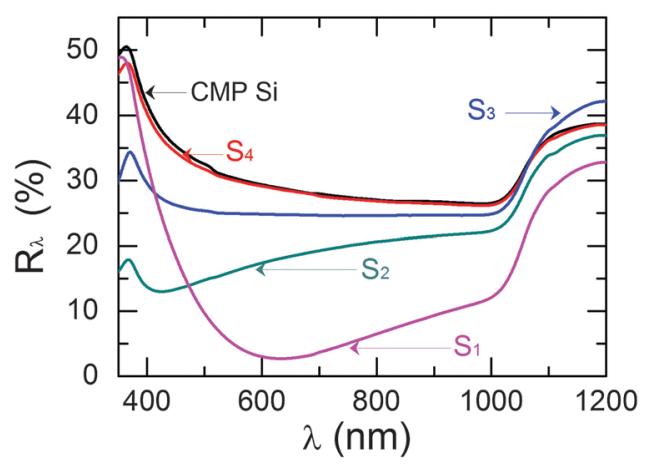

Fig. 4 Reflectivity of samples $S_{1}-S_{4}$ along with that of a CMP wafer. 
relationship; $\lambda_{\text {min }}=4 d_{\mathrm{Al}_{2} \mathrm{O}_{3}} \times n_{\mathrm{Al}_{2} \mathrm{O}_{3}} \cdot{ }^{33,34}$ On the other hand, in the regions away from $\lambda_{\text {min }}$, a combined effect of constructive (i.e., $2 d_{\mathrm{Al}_{2} \mathrm{O}_{3}} \times n_{\mathrm{Al}_{2} \mathrm{O}_{3}} / \lambda=2 \pi$ ) and destructive (i.e., $2 d_{\mathrm{Al}_{2} \mathrm{O}_{3}} \times n_{\mathrm{Al}_{2} \mathrm{O}_{3}} /$ $\lambda=\pi$ ) interferences prevails depending on the path length (extent of $d_{\mathrm{Al}_{2} \mathrm{O}_{3}}$ and $n_{\mathrm{Al}_{2} \mathrm{O}_{3}}$ values) that decides the magnitude of $R_{\lambda} \cdot{ }^{33-35}$ For example, the value of $\lambda_{\text {min }}$ is estimated using the measured $d_{\mathrm{Al}_{2} \mathrm{O}_{3}}(=93 \mathrm{~nm})$ and $n_{\mathrm{Al}_{2} \mathrm{O}_{3}}(=1.65)$ and is found to be $614 \mathrm{~nm}$ for sample $S_{1}$. This value is the same $(=630 \pm 2.5 \% \mathrm{~nm})$ as determined in $\mathrm{S}_{1}$ by spectroscopic measurements within measurement uncertainty. The shift in the $\lambda_{\min }$ position is the manifestation of the change in $d_{\mathrm{Al}_{2} \mathrm{O}_{3}}$ and $n_{\mathrm{Al}_{2} \mathrm{O}_{3}}$. It can be noted that there is a systematic change in $R_{\lambda}$ with the increase in the thickness of the film particularly in the 450 to $1000 \mathrm{~nm}$ range.

Although ALD is generally adopted to deposit ultra thin films, reflectivity studies are carried out to observe the effect of film thickness and their potential to work as an antireflection coating (ARC) in conjunction with passivation properties.

\subsection{FTIR spectroscopy}

Fig. 5 shows the transmittance FTIR spectra of samples $\mathrm{S}_{1}-\mathrm{S}_{4}$. The broad absorption band in the range of $600-400 \mathrm{~cm}^{-1}$ is

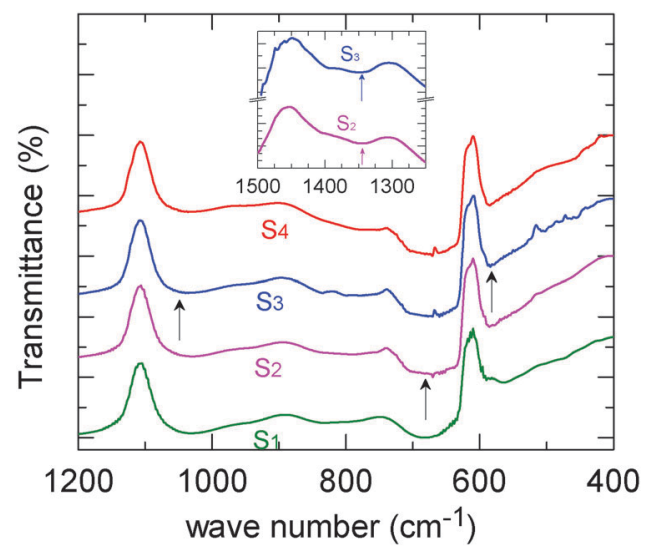

Fig. 5 FTIR spectra of samples $\mathrm{S}_{1}-\mathrm{S}_{4}$. The inset shows an absorbance peak at $\sim 1345 \mathrm{~cm}^{-1}$ due to $\mathrm{Al}=\mathrm{O}$. attributed to the Al-O stretching in the characteristic spectra of $\mathrm{Al}_{2} \mathrm{O}_{3}$. It is reported that a band at $564 \mathrm{~cm}^{-1}$ results from two unresolved structures at 562 and $565 \mathrm{~cm}^{-1}$. The first one is assigned to $\mathrm{Al}-\mathrm{O}$ bending for $\mathrm{AlO}_{6}(5+1)$, while the second to a pure Al-O stretching mode for $\mathrm{AlO}_{4} .^{36}$ The peak observed in the $560-570 \mathrm{~cm}^{-1}$ region (a minor shift with $d_{\mathrm{Al}_{2} \mathrm{O}_{3}}$ ) represents $\mathrm{Al}-\mathrm{O}$ modes. On the other hand, the observed peak in $670-700 \mathrm{~cm}^{-1}$ may be attributed to Al-O stretching mode. ${ }^{37,38}$ The absorption peak at $\sim 710 \mathrm{~cm}^{-1}$ corresponds to the Al-O stretching mode. ${ }^{37,38}$ The peak at $1040-1060 \mathrm{~cm}^{-1}$ is attributed to $\mathrm{Si}-\mathrm{O}-\mathrm{Si}{ }^{37} \mathrm{An}$ absorbance peak due to $\mathrm{Al}=\mathrm{O}$ at $\sim 1345 \mathrm{~cm}^{-1}$ (as shown in the inset of the figure) is also present ${ }^{39}$ but is rather weak whereas in some other reports this peak is not detected. ${ }^{37}$ In all the samples, FTIR spectra show characteristic peaks of $\mathrm{Al}_{2} \mathrm{O}_{3}$.

\subsection{Minority carrier lifetime}

The measured minority carrier lifetime value has contributions from the bulk $\left(\tau_{\mathrm{b}}\right)$ and the surface recombination lifetime $\left(\tau_{\mathrm{s}}\right)$ associated with the wafer surfaces which are related to each other by the following relation; ${ }^{31,40}$

$$
\frac{1}{\tau_{\mathrm{eff}}}=\frac{1}{\tau_{\mathrm{b}}}+\frac{1}{\tau_{\mathrm{s}}}
$$

where $\tau_{\mathrm{s}}$ is equal to $\left(D_{\mathrm{p}} \beta^{2}\right)^{-1}$, which in turn is related to surface recombination velocity $S$ through the relation $\beta \tan (\beta d / 2)=$ $S / D_{\mathrm{p}}$. Here $D_{\mathrm{p}}$ is the diffusion coefficient. In the case of high lifetime material, measured $\tau_{\text {eff }}$ is predominantly a measure of surface recombination.

To evaluate the surface passivation, the upper limit of $S_{\text {eff }}$ is determined from the effective lifetime at an injection level $(\Delta n)$ equal to $10^{15} \mathrm{~cm}^{-3}$ by assuming bulk lifetime very large. Therefore, $S_{\text {eff }}$ gives the worst estimate of the SRV value. Fig. 6 gives a typical photo-conductive decay curve used for the determination of effective lifetime by Sinton's lifetime tester in the transient mode.

It is known that annealing conditions play an important role in surface passivation performance. To optimize the film annealing conditions, a rapid thermal processing technique (RTP) is used which is a low thermal budget process. For a given set of

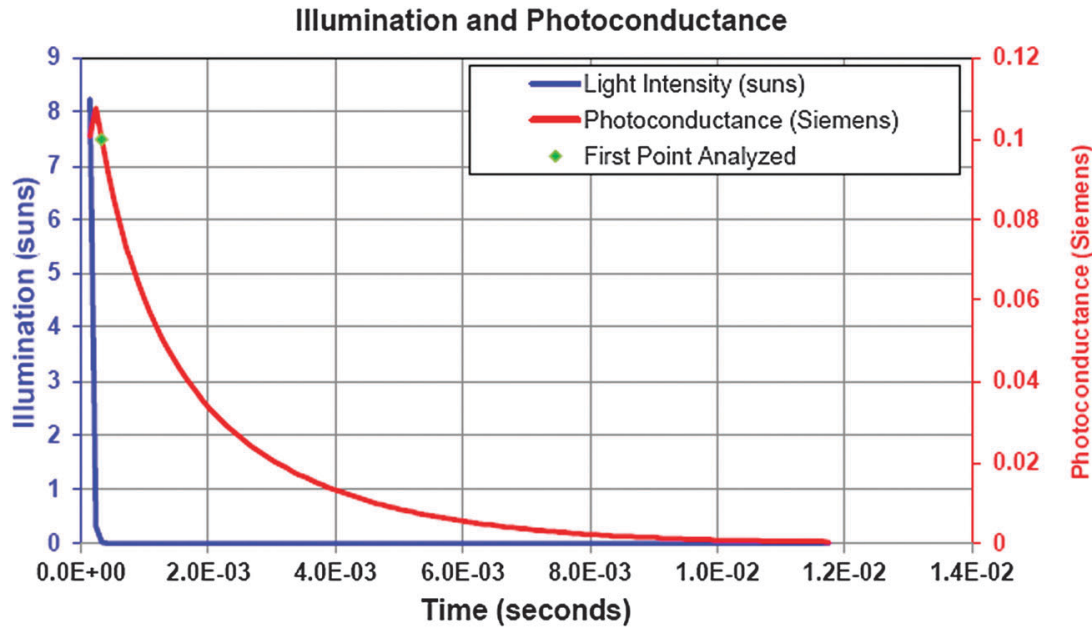

Fig. 6 A typical photo-conductive decay curve obtained by Sinton's lifetime tester in transient mode. 
experiments, annealing temperature is fixed at $400{ }^{\circ} \mathrm{C}$ and annealing time $\left(t_{\mathrm{anl}}\right)$ is varied.

Fig. $7(a-c)$ show effective minority carrier lifetime $\left(\tau_{\text {eff }}\right)$ data as a function of the injection level for as-deposited and annealed samples $S_{2}, S_{3}$ and $S_{4}$ respectively for different annealing time $\left(t_{\mathrm{anl}}\right)$ at fixed $T_{\mathrm{anl}}=400{ }^{\circ} \mathrm{C}$. Lifetime data show a good quality passivation in the entire injection level range $\left(5 \times 10^{13}\right.$ to $\left.1 \times 10^{16} \mathrm{~cm}^{-3}\right)$ in all the three samples. The value of $\tau_{\text {eff }}$ in un-passivated samples is 18 and $1.5 \mu$ s for $n$ - and p-Si respectively which is controlled by SRV values (that is high
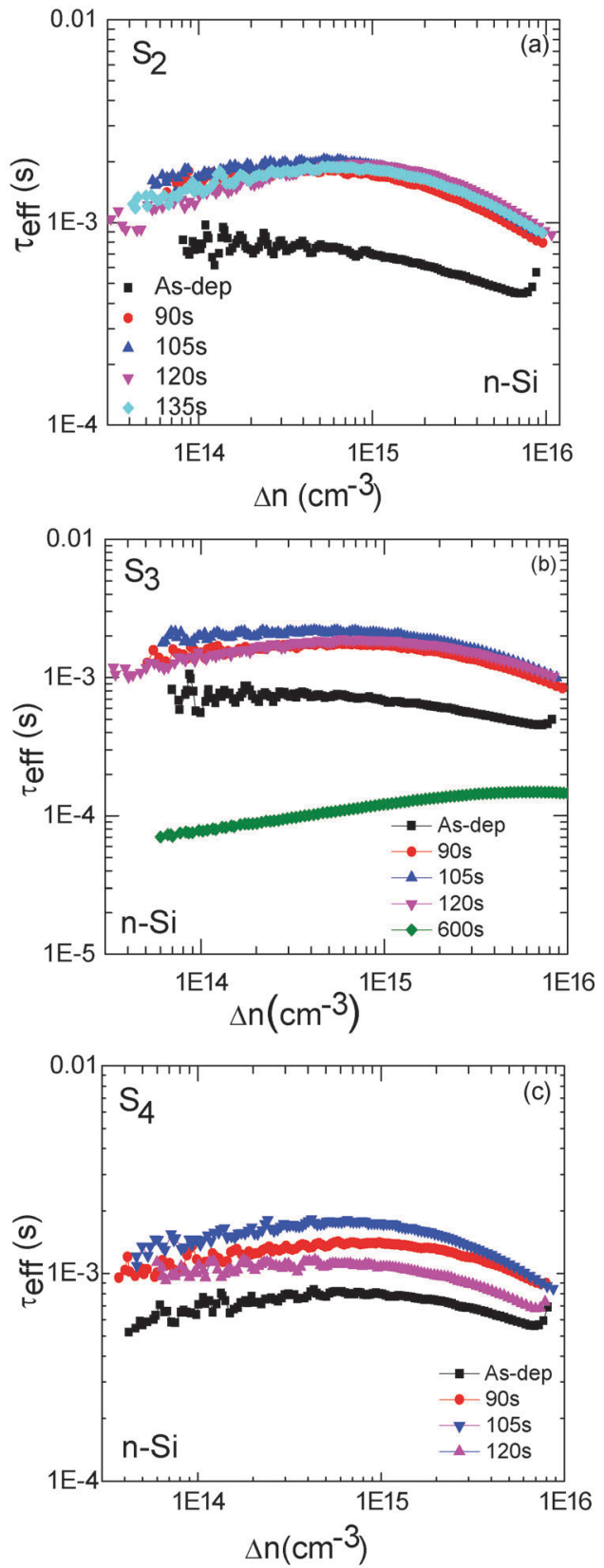

Fig. 7 The measured minority carrier lifetime $\left(\tau_{\text {eff }}\right)$ as a function of the injection level $(\Delta n)$ for $n$-Si samples, $t_{\text {dep }}=300{ }^{\circ} \mathrm{C}$ and $T_{\text {anl }}=400{ }^{\circ} \mathrm{C}$, The data for $S_{2}$ (a) as-deposited and 90, 105, 120 and $135 \mathrm{~s}$ annealed, for $S_{3}(b)$ as-deposited and $90,105,120$ and $600 \mathrm{~s}$ annealed and for $S_{4}$ (c) as-deposited and 90, 105 and $120 \mathrm{~s}$ annealed.
Table 2 Measured minority carrier lifetime $\left(\tau_{\text {eff }}\right)$ and the upper limit of surface recombination velocity (SRV) values for as-deposited samples, at injection level, $\Delta n=1 \times 10^{15} \mathrm{~cm}^{-3}$. The values of $\tau_{\text {eff }}$ and SRV have $\sim 4 \%$ error in their estimation

\begin{tabular}{lccccc}
\hline & $\mathrm{n}-\mathrm{Si}$ & & $\mathrm{p}-\mathrm{Si}$ & \\
\cline { 2 - 3 } \cline { 5 - 6 } Sample & $\tau_{\text {eff }}(\mu \mathrm{s})$ & $\mathrm{SRV}\left(\mathrm{cm} \mathrm{s}^{-1}\right)$ & & $\tau_{\text {eff }}(\mu \mathrm{s})$ & $\mathrm{SRV}\left(\mathrm{cm} \mathrm{s}^{-1}\right)$ \\
\hline Bare & 18 & 903 & 7 & 820 & 10833 \\
$\mathrm{~S}_{1}$ & 2244 & 15 & 678 & 20 \\
$\mathrm{~S}_{2}$ & 1102 & 20 & 430 & 24 \\
$\mathrm{~S}_{3}$ & 824 & 35 & 337 & 48 \\
$\mathrm{~S}_{4}$ & 471 & 158 & 149 & 109 \\
$\mathrm{~S}_{5}$ & 103 & & &
\end{tabular}

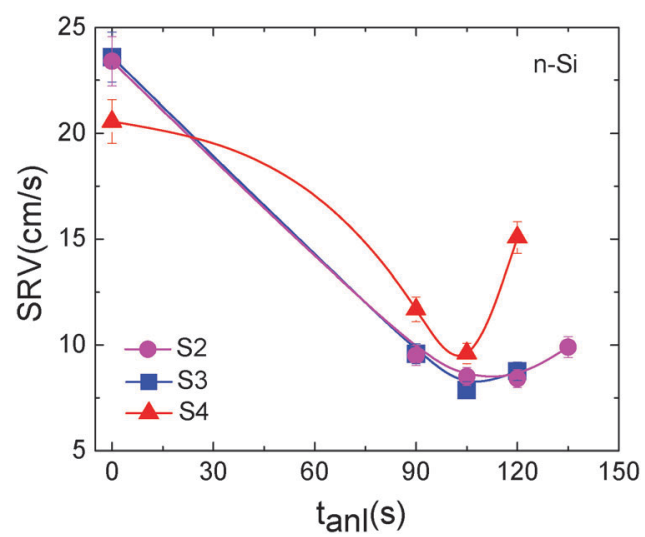

Fig. 8 SRV as a function of sintering time $\left(t_{\text {anl }}\right)$ for sample $S_{2}, S_{3}$ and $S_{4}$. $T_{\text {anl }}=400{ }^{\circ} \mathrm{C}$.

SRV $>10^{3} \mathrm{~cm} \mathrm{~s}^{-1}$ in Table 2, and $>10^{4} \mathrm{~cm} \mathrm{~s}^{-1}$ in ref. 41). An interesting observation is that the measured $\tau_{\text {eff }}$ value increases for shorter sintering time duration, attains its maximum (in the vicinity of $100 \mathrm{~s}$ ) and on further increase in $t_{\text {anl }}$, the value of $\tau_{\text {eff }}$ starts decreasing. This trend is observed in all the samples. Therefore, optimized sintering time for the best passivation is $105 \mathrm{~s}$. It is to be noted that in most of the publications, ${ }^{1,7-10,27}$ annealing is done for longer time durations (10-30 $\mathrm{min}$ ) and there is hardly any publication for shorter $t_{\mathrm{anl}}$.

Table 2 summarizes the measured minority carrier lifetime and corresponding estimated SRV values with films of different thicknesses. It is observed that increase in film thickness improves the surface passivation and a good surface passivation is realized in as-deposited thick films. For example, the lowest SRV values $\left(<10 \mathrm{~cm} \mathrm{~s}^{-1}\right.$ ) are obtained in sample $S_{1}$ (Table $1, \mathrm{n}$-Si). A similar trend is observed in both $\mathrm{n}$ - and $\mathrm{p}$-Si. Surface recombination velocity values for $S_{2}, S_{3}$ and $S_{4}$ samples with annealing duration shows minimum at $\sim 105 \mathrm{~s}$ and the SRV increases both at lower and higher $t_{\mathrm{anl}}$ as can be seen from Fig. 8. Fig. 9 gives an idea about the uniformity of $\tau_{\text {eff }}$ over the sample area where mapping of $\tau_{\text {eff }}$ by the $\mu$-PCD is shown for sample $S_{3}$.

\subsection{Capacitance-voltage measurements: effect of the annealing sequence}

Capacitance measurement as a function of voltage $(C-V)$ is important because it gives vital information about the passivation at the 


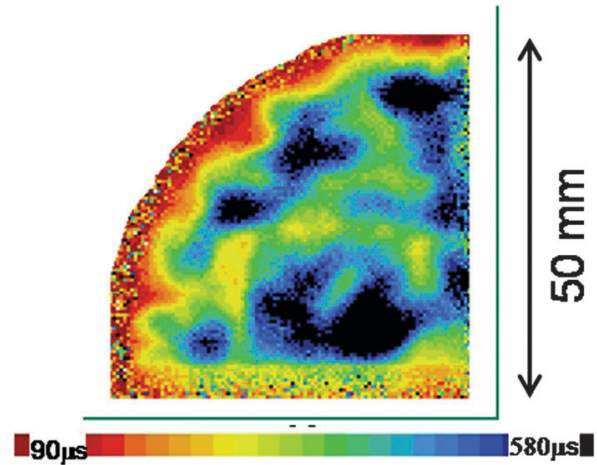

Fig. $9 \mu$-PCD lifetime map of sample $S_{3}$. Figure shows passivation uniformity across the wafer.

$\mathrm{Al}_{2} \mathrm{O}_{3} / \mathrm{Si}$ interface. ${ }^{1,7-10}$ The MIS structure is used for $C-V$ measurements where there is an important step of metal contact formation. Two different experiments (i.e., post and pre-annealing prior to metal contact formation) are carried out to see the effect of the annealing step on $C-V$ characteristics. The MIS structure is made by creating a polka dot pattern of $\mathrm{Al}$ over the $\mathrm{Al}_{2} \mathrm{O}_{3}$ film as described under "Experimental". In the first experiment the annealing step (10 min in $\mathrm{N}_{2}$ ambient) is done after depositing $\mathrm{Al}$ metal whereas in the second experiment the $\mathrm{Al}_{2} \mathrm{O}_{3}$ film is annealed (10 $\mathrm{min}$ in $\mathrm{N}_{2}$ ambient) prior to the formation of metal contacts. The former is referred to as $\mathrm{S}_{\mathrm{MF}}$ and the later as $\mathrm{S}_{\mathrm{AF}}$ in the subsequent text. Fig. 10 shows the $C-V$ data for an as-deposited sample and the two annealed samples; $\mathrm{S}_{\mathrm{MF}}$ and $\mathrm{S}_{\mathrm{AF}}$.

There is a decrease in oxide capacitance in the $S_{\mathrm{MF}}$ sample in contrast to the increase in oxide capacitance with $\mathrm{S}_{\mathrm{AF}}$ condition. Another important observation is that the flat band voltage position is opposite in the two cases. In the sample, where annealing is done prior to metal deposition $\left(\mathrm{S}_{\mathrm{AF}}\right)$ shows positive charge activation. Contrary to this, activation of negative charges occurs when contacts are made prior to annealing $\left(\mathrm{S}_{\mathrm{MF}}\right)$. When aluminum contact is made on the $\mathrm{Al}_{2} \mathrm{O}_{3}$ films and subsequent annealing $\left(\mathrm{S}_{\mathrm{MF}}\right)$ is performed, Al metal may diffuse into the aluminum oxide film that may cause decrease in the capacitance. On the other hand, since the $\mathrm{Al}_{2} \mathrm{O}_{3}$ film is

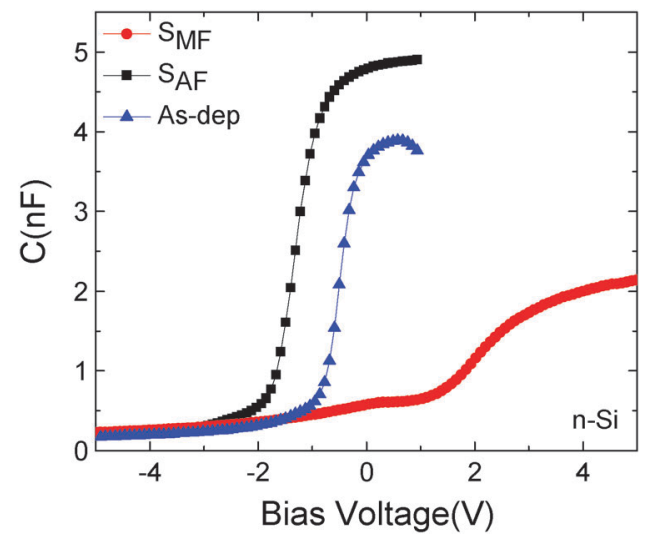

Fig. 10 Capacitance-voltage curves for $S_{3}$. The values are measured in as-deposited and in the two annealed samples; $\mathrm{S}_{\mathrm{MF}}$ and $\mathrm{S}_{\mathrm{AF}}$ at $1 \mathrm{MHz}$.

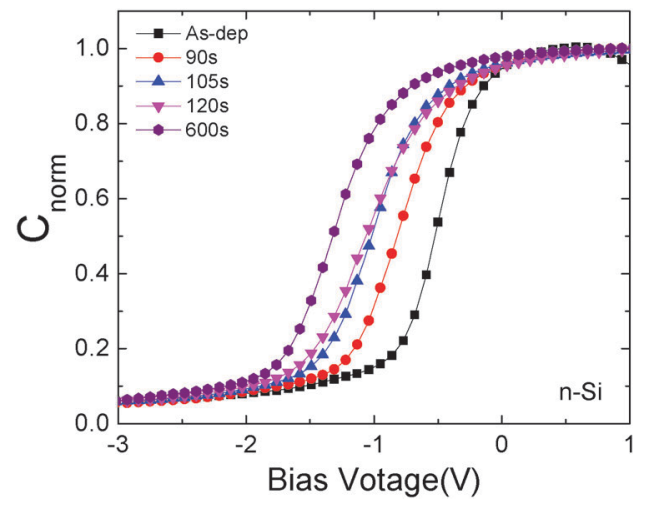

Fig. 11 Normalized $C-V$ curves for $\mathrm{S}_{3}$ measured at $1 \mathrm{MHz}$ for as-deposited and annealed films at 90 s, 105 s, 120 s and 600 s using $S_{A F}$ protocol.

annealed prior to the formation of metal contacts $\left(\mathrm{S}_{\mathrm{AF}}\right)$, no high temperature step is involved after metal deposition. In this case the possibility of $\mathrm{Al}$ diffusion into $\mathrm{Al}_{2} \mathrm{O}_{3}$ is completely ruled out. Consequently, higher capacitance is measured and the $C-V$ data provide a better idea about the film quality and interface properties. Therefore, in the $C-V$ study, the protocol of $\mathrm{S}_{\mathrm{AF}}$ is followed.

As mentioned earlier that silicon surface passivation using $\mathrm{Al}_{2} \mathrm{O}_{3}$ films owes to the combined effect of the field and chemical passivation, which is described in terms of fixed charge density and interface defect density respectively. Field effect passivation is provided by fixed charges located near the $\mathrm{Si} / \mathrm{Al}_{2} \mathrm{O}_{3}$ interface whereas chemical passivation is attributed to hydrogenation at the interface, film relaxation, $\mathrm{Si}-\mathrm{O}$ bond rearrangement or additional oxide growth which may work individually or in tandem. ${ }^{27}$ Fig. 11 shows normalized $C-V$ curves of MIS structures made on as-deposited and annealed $\mathrm{Al}_{2} \mathrm{O}_{3}$ films ( $t_{\mathrm{anl}}=90,105,120$ and $\left.600 \mathrm{~s}\right)$ on $\mathrm{S}_{3}\left(d_{\mathrm{Al}_{2} \mathrm{O}_{3}} \sim 30 \mathrm{~nm}\right)$.

The $C-V$ measurements are carried out at $1 \mathrm{MHz}$ frequency. A negative shift (on abscissa) in the $C-V$ curve with annealing confirms activation of positive fixed charges in the $\mathrm{Al}_{2} \mathrm{O}_{3}$ film on InGaAs substrate. ${ }^{42}$ Low thermal annealing is not very well explored besides observance of post-annealing activation of positive (+ve) charges. Only few publications reported activation of positive charges. Further, the film capacitance increases with annealing as compared to the as-deposited sample. Table 3 compiles the parameters extracted from $C-V$ measurement data. Fixed charge density calculated using the flat band shift shows an increase (in $Q_{\mathrm{F}}$ ) from $0.36 \times 10^{12} \mathrm{~cm}^{-2}$ to $1.34 \times 10^{12} \mathrm{~cm}^{-2}$ whereas interface defect

Table 3 Fixed charge density $\left(Q_{\mathrm{F}}\right)$ and interface defect density $\left(D_{i t}\right)$ in as-deposited \& sintered sample $S_{3}, T_{\text {sint }}=400{ }^{\circ} \mathrm{C}$, n-Si substrate

\begin{tabular}{lll}
\hline$T_{\text {anl }}(\mathrm{s})$ & $Q_{\mathrm{F}}\left(\times 10^{12}\right) \mathrm{cm}^{-2}$ & $D_{\text {it }}\left(\times 10^{12}\right)$ states $/ \mathrm{eV} \mathrm{cm}^{2}$ \\
\hline 0 & 0.36 & 2.96 \\
90 & 0.91 & 1.8 \\
105 & 1.22 & 1.4 \\
120 & 1.34 & 1.5 \\
180 & 0.93 & 2.3 \\
300 & 0.96 & 3.5 \\
600 & 1.59 & 3.3
\end{tabular}


density, $D_{\text {it }}$, decreases from $2.96 \times 10^{12} \mathrm{eV}^{-1} \mathrm{~cm}^{-2}$ to $1.5 \times$ $10^{12} \mathrm{eV}^{-1} \mathrm{~cm}^{-2}$ with $t_{\mathrm{anl}}$ variation from 0 to $120 \mathrm{~s}$. It is reasonable to assume that both chemical and field effects co-exist in $\mathrm{Al}_{2} \mathrm{O}_{3}$ surface passivation. A change in $D_{\mathrm{it}}$ and $Q_{\mathrm{F}}$ values with $t_{\text {anl }}$ gives indication that the two effects work in tandem. An increase in $Q_{\mathrm{F}}$ with $t_{\mathrm{anl}}$ is observed till $120 \mathrm{~s}$ followed by marginal decrease thereafter. An opposite trend is observed in $D_{\text {it }}$ values. The best results (maximum $\tau_{\text {eff }}$ and the lowest SRV) could be obtained in the range where $Q_{\mathrm{F}}$ is maximum and $D_{\text {it }}$ is minimum. In the present case, maximum and minimum values of $Q_{\mathrm{F}}$ and $D_{\text {it }}$ are equal to $1.34 \times 10^{12} \mathrm{~cm}^{-2}$ and $1.4 \times$ $10^{12} \mathrm{eV}^{-1} \mathrm{~cm}^{-2}$ respectively corresponding to $t_{\mathrm{anl}} 120 \mathrm{~s}$ and $105 \mathrm{~s}$ respectively. Therefore, the best $\tau_{\text {eff }}$ or SRV could be realized at $t_{\mathrm{anl}}$ between 105 and $120 \mathrm{~s}$. But for larger annealing duration (>180 s), the $Q_{\mathrm{F}}$ is practically the same and $D_{\mathrm{it}}$ increases which results in an effective decrease in $\tau_{\text {eff. For }}$ $600 \mathrm{~s}$ annealing, although $Q_{\mathrm{F}}$ is higher which is rather surprising as compared to the value obtained after $120 \mathrm{~s}$ annealing, $D_{\text {it }}$ also becomes large (twice compared to the value corresponding to $120 \mathrm{~s}$ ). The two acts in opposite directions and therefore the net effect is degradation in passivation performance (as could be seen in Fig. 7(b)). The magnitude of $Q_{F}$ gets altered after annealing in either direction. On the other hand, $D_{\text {it }}$ is expected to rise if the passivating species (attached to silicon surface or at the interface) get detached with the increase in annealing time. Therefore, the quality of surface passivation is a trade-off between the field effect and chemical passivation and the best passivation (maximum $\tau_{\text {eff }}$ or minimum SRV) could be realized when $Q_{\mathrm{F}}$ and $D_{\text {it }}$, the two quantifying parameters, attain their respective maximum and minimum values at the same annealing temperature. Further, the presence of positive charges may be attributed to the existence of $\mathrm{Al}$ interstitials and $\mathrm{O}$ vacancies. This is in good agreement with the ionic nature of the $\mathrm{Al}_{2} \mathrm{O}_{3} \cdot{ }^{1,10}$

\section{Conclusions}

Silicon surface passivation is studied using $\mathrm{Al}_{2} \mathrm{O}_{3}$ thin films of various thicknesses deposited on the silicon substrate at $300{ }^{\circ} \mathrm{C}$. The $\tau_{\text {eff }}$ values show improvement in surface passivation which is also reflected in SRV values and reflectivity measurements show its utility as an antireflection coating. $C-V$ measurement data show the importance of the annealing step sequence in determining true information about the deposited films. The optimization of process parameters of the $\mathrm{Al}_{2} \mathrm{O}_{3}$ film reveals that $\sim 105 \mathrm{~s}$ annealing time gives best passivation results at $400{ }^{\circ} \mathrm{C}$ wherein $Q_{\mathrm{F}}=1.22 \times$ $10^{12} \mathrm{~cm}^{-2}$ and $D_{\text {it }}=1.4 \times 10^{12} \mathrm{eV}^{-1} \mathrm{~cm}^{-2}$. Therefore, the best surface passivation (maximum $\tau_{\text {eff }}$ or minimum SRV) could be obtained for annealing time in the vicinity of $100 \mathrm{~s}$ and indeed is a trade-off between the field effect (high $Q_{\mathrm{F}}$ ) and chemical passivation (low $D_{\mathrm{it}}$ ). The low thermal budget process (like rapid thermal anneal) activates positive fixed charges (as confirmed by $C-V$ data measurements). The presence of positive charges supports the existence of $\mathrm{Al}$ interstitials and $\mathrm{O}$ vacancies as the primary mechanism for surface passivation of crystalline silicon.

\section{Acknowledgements}

This work was carried out under the NWP-55 grant from Council of Scientific and Industrial Research, India under TAPSUN initiative. NB also thanks CSIR for the research fellowship.

\section{References}

1 B. Hoex, J. J. H. Gielis, M. C. M. van de Sanden and W. M. M. Kessels, J. Appl. Phys., 2008, 104, 113703.

2 A. G. Aberle, Prog. Photovoltaics, 2000, 8, 473-487.

3 International Technology Roadmap for Photovoltaic (ITRPV) 2014; http://www.itrpv.net.

4 P. K. Singh, R. Kumar, M. Lal, S. N. Singh and B. K. Das, Sol. Energy Mater. Sol. Cells, 2001, 71, 103-113.

5 S. K. Srivastava, D. Kumar, Vandana, M. Sharma, R. Kumar and P. K. Singh, Sol. Energy Mater. Sol. Cells, 2012, 100, 33-38.

6 B. Hoex, A. J. M. van Erven, R. C. M. Bosch, W. T. M. Stals, M. D. Bijker, P. J. van den Oever, W. M. M. Kessels and M. C. M. van de Sanden, Prog. Photovoltaics, 2005, 13, 705-712.

7 B. Hoex, S. B. S. Heil, E. Langereis, M. C. M. van de Sanden and W. M. M. Kessels, Appl. Phys. Lett., 2006, 89, 042112.

8 G. Agostinelli, A. Delabie, P. Vitanov, Z. Alexieva, H. F. W. Dekkers, S. DeWolf and G. Beaucarne, Sol. Energy Mater. Sol. Cells, 2006, 90, 3438-3443.

9 B. Hoex, J. Schmidt, P. Pohl, M. C. M. van de Sanden and W. M. M. Kessels, J. Appl. Phys., 2008, 104, 044903.

10 K. Matsunaga, T. Tanaka, T. Yamamoto and Y. Ikuhara, Phys. Rev. B: Condens. Matter Mater. Phys., 2003, 68, 085110.

11 P. Saint-Cast, D. Kania, M. Hofmann, J. Benick, J. Rentsch and R. Preu, Appl. Phys. Lett., 2009, 95, 151502.

12 J. Benick, B. Hoex, M. C. M. van de Sanden, W. M. M. Kessels, O. Schultz and S. W. Glunz, Appl. Phys. Lett., 2008, 92, 253504.

13 P. Saint-Cast, J. Benick, D. Kania, L. Weiss, M. Hofmann, J. Rentsch, R. Preu and S. W. Glunz, IEEE Electron Device Lett., 2010, 31, 695-697.

14 B. Liao, R. Stangl, T. Mueller, F. Lin, C. S. Bhatia and B. Hoex, J. Appl. Phys., 2013, 113, 024509.

15 J. Schmidt and A. Cuevas, J. Appl. Phys., 1999, 85, 3626-3633. 16 M. J. Kerr and A. Cuevas, Semicond. Sci. Technol., 2002, 17, 166-172.

17 S. de Wolf, G. Agostinelli, G. Beaucarne and P. Vitanov, J. Appl. Phys., 2005, 97, 063303.

18 M. Schaper, J. Schmidt, H. Plagwitz and R. Brendel, Prog. Photovoltaics, 2005, 13, 381-386.

19 T. F. Schulze, H. N. Beushausen, C. Leendertz, A. Dobrich, B. Rech and L. Korte, Appl. Phys. Lett., 2010, 96, 252102.

20 S. de Wolf, B. Demaurex, A. Descoeudres and C. Ballif, Phys. Rev. B: Condens. Matter Mater. Phys., 2011, 83, 233301-233304.

21 A. Illiberi, M. Creatore, W. M. M. Kessels and M. C. M. van de Sanden, Phys. Status Solidi RRL, 2010, 4, 206-208.

22 T. A. Li, S. Ruffell, M. Tucci, Y. Mansoulié, C. Samundsett, S. De Iullis, L. Serenelli and A. Cuevas, Sol. Energy Mater. Sol. Cells, 2011, 95, 69-72. 
23 K. O. Davis, K. Jiang, M. Wilson, C. Demberger, H. Zunft, H. Haverkamp, D. Habermann and W. V. Schoenfeld, Phys. Status Solidi RRL, 2013, 7, 942-945.

24 T.-T. Li and A. Cuevas, Phys. Status Solidi RRL, 2009, 3, 160-162.

25 C. Cibert, H. Hidalgo, C. Champeaux, P. Tristant, C. Tixier, J. Desmaison and A. Catherinot, Thin Solid Films, 2008, 516, 1290-1296.

26 M. T. Seman, D. N. Richards, P. Rowlette and C. A. Wolden, Chem. Vap. Deposition, 2008, 14, 296-302.

27 G. Dingemans and W. M. M. Kessels, J. Vac. Sci. Technol., A, 2012, 30, 040802.

28 J. Wang, S. S. Mottaghian and M. F. Baroughi, IEEE Trans. Electron Devices, 2012, 59, 342-348.

29 R. Lago-Aurrekoetxea, I. Tobías, C. del Cañizo and A. Luque, J. Electrochem. Soc., 2001, 148, G200-G206.

30 C. Berge, J. Schmidt, B. Lenkeit, H. Nagel and A. G. Aberle, 2nd World Conference on Photovoltaic Solar Energy Conversion, 1998, 1426-1429.

31 N. Batra, Vandana, S. Kumar, M. Sharma, S. K. Srivastava, P. Sharma and P. K. Singh, Sol. Energy Mater. Sol. Cells, 2012, 100, 43-47.

32 J. Lekner, Theory of Reflection of Electromagnetic and Particle Waves, Developments in Electromagnetic Theory and Applications,
Springer Science Media Busniss BV, 1987, vol. 3 (ISBN 978-94015-7748-9).

33 A. Nussbaum and R. A. Phillips, Contemporary Optics for Scientists and Engineers, Prince-Hall, Englewood Cliffs, NJ, 1974.

34 J. Zhao and M. A. Green, IEEE Trans. Electron Devices, 1991, 38, 1925.

35 Vandana, N. Batra, P. Kumar, P. Sharma and P. K. Singh, Mater. Chem. Phys., 2014, 144, 242.

36 L. Favaro, A. Boumaza, P. Roy, J. Lédion, G. Sattonnay, J. B. Brubach, A. M. Huntz and R. Tétot, J. Solid State Chem., 2010, 183, 901-908.

37 R. Katamreddy, R. Inman, G. Jursich, A. Soulet and C. Takoudis, J. Electrochem. Soc., 2006, 153(10), C701-C706.

38 M. Ben Rabha, M. Salem, M. A. Khakani, B. Bessais and M. Gaidi, Mater. Sci. Eng., B, 2013, 178, 695-697, DOI: 10.1016/j.mseb.2012.11.021.

39 Z. Katz-Tsameret and A. Raveh, J. Vac. Sci. Technol., A, 1995, 13, 1121-1127.

40 A. W. Stephens and M. A. Green, Sol. Energy Mater. Sol. Cells, 1997, 45, 255-265.

41 S. Kumar, P. K. Singh and S. R. Dhariwal, Appl. Phys. Lett., 2010, 96, 162109-162111.

42 B. Shin, J. R. Weber, R. D. Long, P. K. Hurley, C. G. Van de Walle and P. C. McIntyre, Appl. Phys. Lett., 2010, 96, 152908. 